\title{
Coda: Charting Future Directions of Music Cognition in turbulent times
}

\author{
Joshua Albrecht ${ }^{\dagger}$ \\ ${ }^{1}$ Hugh A. Glauser School of Music, Kent State University, Kent, OH, USA \\ Published 16 December 2021; https://doi.org/10.18061/FDMC.2021.0054 \\ †Corresponding author: jalbrec6@kent.edu
}

\begin{abstract}
The Future Directions of Music Cognition conference and speaker series incorporated hundreds of scholars presenting their research and dialoguing about what future directions the field of music cognition may take. This proceedings volume fairly represents much of the activity at the conference proper. However, it is difficult for a conference about the future of an academic field to live up to its name during a time of such rapid societal change. This article attempts to partially address this gap by thinking through the implications current events may have on future directions of music cognition. It is a speculative investigation of three primary issues: social justice and anti-racism, the changing role of science in society, and the challenges of fostering an environment of healthy dialogue in inhospitable times.
\end{abstract}

\section{Music cognition's possible future directions}

Now that Future Directions of Music Cognition has finally come to a close at the end of a tumultuous two years, it is reasonable to ask whether this conference and speaker series has led us any closer to understanding what the future of music cognition might hold. Of course, a lot more has happened in the last two years than just this conference; the last eighteen months have been marked more by unpredictability than stability. Undoubtedly, this turbulent time has carried many powerful lessons that are worthy of careful thought and reflection, not least of which is to be cautious about being too certain about the future.

Many recent publications in 2020 and 2021 are in the unfortunate position of being immediately out of date at the moment of their publication. Unfortunately, Future Directions is not immune from this problem, having been conceived before COVID and many other significant changes that have left sizeable impacts on society. At the same time, many things about the conference were able to pivot in response to current events, especially the speaker series, as the introduction outlines (pp. 1-3). However, these proceedings mostly represent the conference submissions, which were all received before the end of 2019, and so several current research trends are not reflected in these pages. To give just one example, a wealth of recent research explores ways in which the pandemic, social distancing, and online behaviors have interacted with our musical behaviors and cognition.

Future Directions is by any account an ambitious project, and even with content contributed by 150 authors, these proceedings provide just a slice of the significant current and future trends in music cognition. Consequently, in planning the conference we were careful to omit the definite article "the" from the title of this conference. Even at that time, we knew there would be many other future directions of music cognition not represented in these pages. This is certainly more true in 2021 than it was in 2019. Even still, I believe we may detect some clues about directions the field might be moving in by looking at patterns of what was presented at the conference and the articles in this proceedings.

In this essay, I aim to explore some of the possible future directions of music cognition by attempting to retrospectively connect the work represented in this volume to some of the current societal forces that seem to be shaping not only the future of society at large, but also specifically of music cognition. Rather than simply reviewing the contents of these proceedings, I propose the slightly more ambitious goal in this essay of thinking through the intersections between current events and music cognition as a way of bringing the mission of the conference full circle. I believe that the research presented at the Future Directions conference interfaces in important ways with some of these current events. Having said that, it is important to underline that the following are my own thoughts that may not represent those of other conference participants. Of course, the COVID-19 pandemic is only one of many major societal shifts in the last eighteen months that have impacted the future of music cognition. The last couple of years represent an inflection point for the arts, sciences, and society at large.

I do not have the capacity here to do justice to all the factors likely to impact music cognition in the 
future. For example, concerns about climate change have already influenced the way that conferences are organized, and even after the pandemic has subsided efforts will undoubtedly continue to reduce the carbon footprint of music cognition societies and conferences. The financial impacts of the pandemic on universities has greatly reduced the amount of professional development and travel funds open to faculty and has resulted in hiring freezes. The dearth of new jobs has hit recent graduates the hardest. Coupled with the lack of networking opportunities through the near elimination of face-to-face conferences, these changes threaten the careers of a generation of researchers. In the United States, the realities of upcoming demographic changes mean the probable reduction of the number of students attending universities, which will also negatively impact research funding and productivity.

These and many other significant issues will all impact future directions of music cognition, but this essay will focus on three main issues: social justice and anti-racism, the changing role of science in society, and the challenges of fostering an environment of healthy dialogue at a time in which intolerance to others' perspectives and moral outrage are growing, while listening to others and compassion are declining.

\section{Calls for social justice and anti-racism}

In the wake of the murder of George Floyd in May 2020, a worldwide movement sprang up to grapple with the realities of a still all-too-pervasive racism in the United States and across the world. Unprecedented levels of demonstrations, activism, and protests calling for society to be more just for all people marked the summer of 2020 and beyond. Protests emerged in over 2,000 cities and towns and all 50 states in the following year related to civil rights, criminal justice, policing, and racism (Crowd Counting Consortium, 2021). The voices of individuals who have not been heard for too long suddenly had a bigger platform.

Many within music cognition have also begun actively working toward greater social justice. Recognizing the reality that there is no such thing as pure scientific objectivity and that echoes of racism continue to influence even the field of music cognition, the SMPC executive board together published an article in Music Perception urging the research community to embrace anti-racist practices (Baker et $a l ., 2020)$. Following up on this article as part of the Future Directions speaker series, several members of the SMPC board led a participatory town hall discussion about anti-racism (Gather Town, 2021). This session generated discourse and ideas among conference participants to stimulate change in the Society, focusing on problems with representation among music cognition researchers and publications, the 'leaky pipeline' of training underrepresented students, past explicit racism in methods used, and a lack of diversity and inclusion among participants that has led to results that do not readily generalize to all people.

There are already signs that researchers are taking these calls to action seriously by challenging prior research practices and broadening the scope of current and future research. During the speaker series, Justin London (London, 2021) argued that corpus studies are weakened by over-reliance on the same canonical works by Bach, Haydn, Mozart, and Beethoven, leading to results that are overfit to just these composers and do not represent broader compositional activity. Daniel Shanahan (Shanahan, 2021) provocatively suggested that the heavily Western European-centric Essen folksong database be retired for corpus research or used only as a sandbox dataset, due to its overuse and monocultural representation. Both speakers suggested a broader sample of music that should be encoded, and they also discussed important efforts already underway to diversify corpora, as well as the importance of centering the voices of scholars from underrepresented groups and being cognizant of the biases inherent in such empirical approaches to music research.

In these proceedings, two articles in particular explicitly study the music cognition of Black musicians. Jason Winikoff (pp. 262-266) explores the mental processes that Zambian Luvale ngoma drummers rely on to create interlocking composite melodies from multiple different types of drums. Hannah Merseal, et al. (pp. 91-92) conducted a corpus study on jazz solos from the Weimar Jazz Database and found that jazz musicians tend to retrieve "easier" melodic sequences in jazz solos before moving on to more complex ideas. It is likely that future music cognition research will continue to push into more diverse research topics and repertoire, incorporate more research on/by/with individuals from underrepresented groups, and further grapple with the role of anti-racism in music cognition. 


\section{"Following the science"}

Living in a worldwide pandemic has brought science into the popular imagination in a much more immediate way than it has been in recent memory. The breathtakingly rapid development of several COVID19 vaccines in record time has highlighted the important role that scientific research plays in the health and wellbeing of the world's population. Hearing directly from scientific leaders almost daily through interviews and press briefings has suddenly become a common experience for the general public, as many search out the best scientific evidence regarding policies like wearing masks, being vaccinated, and optimal distancing to avoid spreading the virus. At the same time, public debate has erupted over some of these policies, leading to a much stronger public interest in the nature of scientific claims. Consequently, opinions about scientific research among the public have rapidly multiplied and these opinions are more fiercely held now than they have been in recent memory. In the United States and elsewhere, the phrase "follow the science" has entered the common vernacular. Even political slogans have embraced the phrase as a way of combating what some see as "science deniers."

One consequence of the sudden celebrity or notoriety of science (depending on one's perspective) is that the public is now at once much more aware of some of the issues surrounding scientific findings and methodology. Another consequence is that scientific evidence and reporting has become politicized, pushing scientists into the forefront of public awareness, sometimes in ways that can be unwelcome for researchers. Aware of these forces, the Organization for Economic Co-operation and Development's "Science, Technology and Innovation Outlook" has recently published advice for scientists to communicate with the public in ways that are both effective and foster trust in science (OECD, 2021).

Music cognition research represents a tiny fraction of the global scientific community. However, the current public interest in science presents both opportunities and risks for the future of music cognition research. One side effect of greater public interest in science generally is a corresponding greater public exposure to music cognition research. Public exposure both raises researchers' responsibilities to conduct sound, reproducible research, and also enhances the possible public benefits of music cognition research. Those who seek to see their research directly benefit real people have wonderful new opportunities to have their work platformed in ways that echo Psyche Loui's (pp. 25-31) article on use-inspired music cognition. In it, she calls for a deeper integration of pure music cognition research with practical applications of music-based interventions that can make the world a better place.

Music cognition seems to be peculiarly well positioned to benefit people during a global pandemic, in which there are unprecedented levels of social isolation and emotional trauma. For example, Zachary Wallmark's speaker series talk (Wallmark, 2021) explores the way that music can enhance empathy and provide a sort of virtual human presence in times of social isolation. This kind of music research, geared toward addressing immediate societal needs, is likely to become more prevalent in upcoming years and is well suited to help people and influence public policy.

However, it is also important to recognize that "follow the science" as a slogan is somewhat misleading, erroneously suggesting that science speaks with one unified voice. On the contrary, science is a method, not a monolithic authority that makes pronouncements about what is definitively true. Consensus among researchers is certainly sometimes possible, but healthy scientific communities foster debate. The certainty suggested by the phrase "follow the science" and the kinds of popular news reporting of scientific results is a mischaracterization of the scientific enterprise, and if followed by limitations on the scope of debate it will only hinder scientists' ability to effectively generate research. Music cognition is an inherently interdisciplinary field and is a particularly striking illustration of the benefits of healthy dialogue and the convergence of multiple research methods across both the humanities and the sciences. This volume is a prime example of the intersection of multiple methods, containing research on similar topics supported by empirical studies, theoretical investigations, and policy proposals.

To take one example, there are still a variety of viable perspectives about the nature and origins of musical emotion, reflected in Future Directions contributions. One dominant paradigm conceives of musical emotion along dimensional lines, embraced by several researchers in this volume, such as Thery Al Alam and Nicola Dibben (pp. 97-101). By contrast, Lindsay Warrenburg (p. 139) argues that even researchers using discrete emotion terms have fallen prey to semantic underdetermination, conflating multiple emotions under the same term, and should 
increase the emotional granularity of their studies through more refined emotion terms. Mark Riggle (pp. 119-124) offers a theoretical evolutionary explanation of the role that musical pleasure plays in sexual selection, arguing that music evoked emotions serve as tools for memory enhancement. In her speaker series talk, on the other hand, Jonna Vuoskoski (Vuoskoski, 2021) focuses on the role that musical emotion plays in building social empathy, specifically exploring the more abstract feeling of 'being moved' as a way of understanding others' emotional states and activating deeper social bonds and prosocial behavior. Tanushree Agrawal, et al. (p. 145) experimentally explore this idea in a novel way, finding that participants are more reluctant to inflict physical harm on subjects that are perceived as more musical, underscoring music's prosocial role. Finding space for these types of vibrant discussions to take place is crucial to continuing to grow our understanding of the nature of musical emotion and the future of music cognition as a whole.

\section{Fostering healthy dialogue}

However, finding space for healthy, vibrant dialogue has been becoming more challenging lately. As the chair of the program committee, one of my responsibilities has been to foster dialogue and create space on the program for many diverse voices. Having such a complex group of viewpoints and subfields among the conference submissions offered its own set of programming challenges. However, recent years have witnessed the rise of other challenges to the kinds of free, open, and honest discussions out of which the best research and teaching flourishes.

In his monumental review of the history of ideas in the 20th century, Peter Watson argues that what is so refreshing about science is that, "[i]t has no real agenda. What I mean is that by its very nature science cannot be forced in any particular direction. The necessarily open nature of science...ensures that there can only ever be a democracy of intellect in this...To succeed, to progress, the world must be open, endlessly modifiable, unprejudiced" (Watson, 2001: 4). This idealistic understanding of science is attractive, but is unfortunately also overly simplistic and naïvescientists have complicated mixtures of motivations for the research they conduct, and there is a long history of documented methodological pitfalls, innocent mistakes, research prejudices, and publishing malpractices that undermines the objectivity of research and pushes it in biased directions.
Nevertheless, there is also an important underlying principle in Watson's comment that is embedded in the very nature of scientific inquiry itself - the freedom and honesty to pursue lines of inquiry wherever they lead. Those who have engaged in research long enough know that results are not always consistent with $a$ priori hypotheses. Research sometimes fails, and even well-loved theories can be overturned. Many of the scientific community's greatest successes and advancements of knowledge have flowed directly from the freedom to engage in controversial lines of research honestly, publish unpopular results, and pursue research that doesn't result in immediate commercial profit.

Unfortunately, in recent years there has been a surge of strong cultural undercurrents that work to shut down dialogue and silence voices. One of these undercurrents, made more concerning because it comes directly from the governments that are designed to protect freedom of speech themselves, is a spate of recent restrictions on teaching various elements about racial justice. As of this writing, eight states in the US have passed laws restricting the teaching or training of specific racial justice concepts or ideas. While most of these laws focus on public K-12 and charter schools, the laws in Idaho, Oklahoma, and Iowa pertain to public universities, as well (Legislature of the State of Idaho, 2021; House Bill 1775, 2021; The Iowa Legislature, 2021). Twenty additional states are considering similar legislation, with six of these bills (Alabama, Kentucky, Louisiana, Missouri, Pennsylvania, and Wisconsin) limiting speech in institutions of higher learning. Thankfully, none of these bills prohibits research on these topics, and so music cognition researchers who wish to engage with and publish these ideas in their research may continue to do so. But, many of the bills would prohibit this research from trickling down into coursework. As mentioned above and as reflected in the content of the Future Directions conference, many members of the SMPC community and others have begun examining racial justice issues, and these new state regulations could have a dampening effect on what is a burgeoning area of research. Beyond just this topic, though, any state restrictions on what can be taught sets a concerning precedent.

There are also broader cultural and institutional pressures limiting how academics communicate about research, especially with the general public. Rider and Peters (2018: 5) describe what they call a "post-truth" society in which traditional cultural reference points 
that once built shared meaning break down, such as the role universities once had as "truth tellers." In a posttruth society, individuals' conceptualizations of facts and evidence become politically and socially reconstructed, opening the possibility for the alt-right, neoliberalism, and illiberalism to take on a greater role as society's gatekeepers definers of truth. Oleksiyenko and Jackson (2021: 1058) have highlighted the way in which these movements have taken advantage of posttruth contexts to "pervert notions of freedom of speech, making universities battlefields of politicized emotions and expressions," using academic freedom as cover for new types of institutional proselytizing. An increasingly common response from legacy "truth teller" institutions to the fracturing of culturally-shared meaning is to restrict freedom of speech - according to Gibbs (2019), academic freedom has never been challenged as much as it is today. These overreactions against problematic speech in academia have led to broader "decline and corruptions of democratic free speech and academic freedom, or the forces to defend them" (Oleksiyenko and Jackson, 2021: 1058).

Under the circumstances, what is a scholar wishing to participate in Loui's (pp. 25-31) vision of communicating practical research to the public to do? Complicating issues even further are rapidly shifting norms of what is deemed appropriate public scientific discourse, especially in the realm of social media. The rigidity with which posts and users are banned from communicating about what in reality are still open scientific questions implies a scientific certainty that just does not exist in most cases. While much of the focus in the past year has rightly been on scientific misinformation surrounding COVID, other social and cultural issues have become flashpoints for public campaigns to officially sanction or even fire professors, and a university faculty's social media post that may be culturally acceptable when published could later become the impetus for public outcry. This problem is consistent with Gibbs's concept of an "erosion of trust [in universities] in a context where free speech interacts with social media and all are subject to the force of the transient present" (Gibbs, 2019: 502).

An atmosphere in which public opinion can shift so quickly and have such deep impacts on researchers can be particularly chilling for healthy academic discourse. To take one example, Väliverronen and Saikkonen (2021) documented the effect that the rise of the rightwing populist Finns Party has had on self-censorship among Finnish researchers. 881 surveys were collected in 2015, 2017, and 2019, during the period when the Finns Party first attained political power and then lost it again but remained publicly popular. Over this time, they documented strong concerns about "anti-science sentiment" among researchers, coming not only from the government, but also from "online hate, aggressive feedback, and politically motivated disparagement of scientists and experts" (Väliverronen and Saikkonen, 2021: 8). The high levels of self-censorship that often result from a culture of normalized aggressive attacks, whether online or not and coming from any political position, deeply undermines healthy scientific discourse and disincentivizes researchers from communicating with the public for fear of the negative consequences to their career and reputation.

Touching on these important but difficult issues in his article, David Huron (p. 13) applauds the intentions of the growing number of researchers who consider themselves activists to change the world for the better. However, he warns about the inherent danger this strategy results in of rushing to moral judgments of others as bad people rather than fairly and empirically testing the effectiveness of those ideas. Huron suggests that public musicologists who are trained as social activists but lack sound methodological training are more likely to fail in their efforts to transform society for the good.

Research flourishes in environments in which scholars are free to pursue whatever lines of research seem most pressing and to follow the evidence wherever it leads. Although it can sometimes be uncomfortable for voices with minority viewpoints to be heard, the alternative is to suppress the ideas of those with unpopular perspectives. As mentioned above, this is one of the very mistakes academia committed in the bad old days in which racism explicitly suppressed the speech of those not in power. When an individual's ability to speak in an academic discipline is dependent on how much power they have, academia trades in its lofty mission of pursuing knowledge wherever it leads for the much more impoverished mission of simply reinforcing popular, well-loved theories or the narratives of those already in power. A culture in which fear of reprisal prevents researchers from honestly engaging in controversial research or publishing unpopular results decimates healthy dialogue and undermines the scholar's ability to serve society. As the field of music cognition moves forward into the future, how it navigates the polarizing tensions pent up in these cultural and societal forces will not only influence the degree to which healthy 
dialogue will be fostered or hampered but also the field's ability to transform society for the good and benefit real people.

\section{Conclusion}

The Future Directions of Music Cognition conference and speaker series brought together hundreds of scholars from all over the world to hear about new research, learn about the most currently influential methods and approaches from several subfields, and to foster healthy conversations about the state of field in light of some of the issues that have recently become important. This sort of endeavor-scholars coming together to think and dream about the future of the field - is exceptionally important, especially in difficult times. The decentralized, international, interdisciplinary, collaborative, and methodologically and ideologically diverse nature of efforts like this conference and speaker series underscore the richness and diversity of music cognition, and the promise of the future of the field. Charting future directions of music cognition in turbulent times is fraught with many difficulties, but one of the lessons of this conference is that the effort is better met together in community.

\section{Acknowledgements}

I am deeply grateful to the conference participants, speaker series presenters, session moderators, and submission reviewers whose contributions comprise this whole endeavor. Lindsay Warrenburg and Lindsey Reymore deserve the most credit for the conference, serving as hosts and who were the original impetus for the conference. Many thanks to Daniel Shanahan for supervising the entire endeavor and providing his expertise in making this possible. I also want to thank the Ohio State University library and Knowledge Bank staff for all the work involved in publishing these proceedings. Deep gratitude to the team at the Open Science Framework for hosting conference presentations and supplemental materials for the indefinite future. Finally, we thank our generous sponsors, the Ohio State Energy Partners and Ohio State's Center for Cognitive and Brain Sciences for funding the conference and speaker series.

\section{References}

Baker, D.J, Belfi, A., Creel, S., Grahn, J., Hannon, E., Loui, P, Margulis, E.H., Schachner, A., Schutz, M., Shanahan, D., \& Vuvan, D. (2020). Embracing antiracist practices in the music perception and cognition community. Music Perception: An Interdisciplinary Journal 38(2): 103-105. https://doi.org/10.1525/mp.2020.38.2.103

Crowd Counting Consortium. (2021, September 9). CCC Data Dashboard; Civil Rights, Criminal Justice, Policing, and Racism protests in the US from May 26, 2020 through May 26, 2021. https://sites.google.com/view/crowdcountingconsortium/ home.

Gather Town. (2021). Town Hall on Anti-Racism in Music Cognition.

https://gather.town/app/BYatfy3d9rD3cwA0/FD_antirac ismTH

Gibbs, P. (2019). Why academics should have a duty of truth telling in an epoch of post-truth? Higher Education, 78, 501-510. https://doi.org/10.1007/s10734$\underline{018-0354-\mathrm{y}}$

House Bill 1775. (2001). An Act. http://webserver1.lsb.state.ok.us/cf pdf/202122\%20ENR/hB/HB1775\%20ENR.PDF

London, J. (2021). Music Theory as Junk Science. Open Science https://doi.org/10.17605/OSF.IO/Y5W2Z

Legislature of the State of Idaho. (2001). House Bill 377. https://legislature.idaho.gov/wpcontent/uploads/sessioninfo/2021/legislation/H0377.pdf

OECD. (2021). OECD Science, Technology and Innovation Outlook 2021: Times of Crisis and Opportunity. Paris: OECD Publishing. https://doi.org/10.1787/75f79015-en

Oleksiyenko, A.V. \& Jackson, L. (2021). Freedom of speech, freedom to teach, freedom to learn: The crisis of higher education in the post-truth era. Educational Philosophy and Theory, 53(11), 1057-1062. https://doi.org/10.1080/00131857.2020.1773800

Rider, S. \& Peters M.A. (2018). Post-truth, fake news: Viral modernity and higher education. In M.A. Peters, S. Rider, M. Hyvönen, \& Tina Besley (Eds.), Post-Truth, Fake News: Viral Modernity \& Higher Education (pp. 3-12). Singapore: Springer. https://doi.org/10.1007/978981-10-8013-5 1

Shanahan, D. (2021). What the history of computational musicology can tell us about the future of corpus studies. Open Science Framework. https://doi.org/10.17605/OSF.IO/CB26R

The Iowa Legislature. (2021, June 8). House File 802. https://www.legis.iowa.gov/legislation/BillBook?ga=89 $\& \mathrm{ba}=\mathrm{HF} 802$ 
Väliverronen, E. \& Saikkonen, S. (2021). Freedom of expression challenged: Scientists' perspectives on hidden forms of suppression and self-censorship. Science, Technology, \& Human Values, 46(6): 11721200. https://doi.org/10.1177/0162243920978303

Vuoskoski, J. (2021). From compassion to being moved: Social emotions evoked by music. Open Science Framework. https://osf.io/sb4hv/

Wallmark, Z. (2021). Future Directions presentation_Zachary Wallmark. Open Science Framework. https://doi.org/10.17605/OSF.IO/9MGHN

Watson, P. (2001). The Modern Mind: An intellectual history of the $20^{\text {th }}$ century. New York, NY: HarperCollins Publishers. 